\title{
Communicable Diseases Report, New South Wales, for November and December 2006
}

\section{Communicable Diseases Branch, NSW Department of Health}

For updated information, including data and facts on specific diseases, visit www.health.nsw.gov.au and click on Infectious Diseases.

\section{Trends}

Tables 3 and 4 and Fig. 4 show reports of communicable diseases received through to the end of November and December 2006 in NSW. There was an increase in notifications of cryptosporidiosis in November (see http://www.health.nsw.gov.au/data/diseases/cryptosporidiosis.html) largely from the New England and mid western regions of the state.

\section{Three cholera cases linked to eating raw imported whitebait}

In late November an infectious disease physician with Sydney South West Area Health Service reported that Vibrio bacteria had been identified in the stools of three women with diarrhoea. Subsequent testing of the bacteria confirmed that it was Vibrio cholerae O1 Ogawa El Tor, which is able to produce cholera toxin.

Investigation identified that the only common exposure amongst the women was eating raw whitebait while preparing it for cooking at home. A subsequent trace back investigation by the NSW Food Authority revealed that a single supplier from Indonesia had imported the implicated food, and a media release was issued urging people to avoid eating raw whitebait. Active surveillance was instituted but no further cases of cholera were discovered. The three women subsequently recovered.

\section{Outbreak of Salmonella Montevideo infections}

An increase in the number of notifications of patients with Salmonella Montevideo infection was identified in November (16 compared with a mean of two for November during each of the previous 5 years). The patients resided throughout the Sydney metropolitan area and the Hunter New England Area. No clustering has been identified among cases to date. Public health units have been asked to interview patients using a standard questionnaire in an attempt to identify common exposures.

\section{Two blue families: unintentional ingestion of sodium nitrate}

In September, a Chinese couple presented to a Sydney South West hospital with vomiting, drowsiness and cyanosis. Two weeks later three members of a Vietnamese family presented to the same hospital with severe vomiting and cyanosis. A fourth member of the second group also became ill but spontaneously recovered without seeking medical intervention. In both instances clinicians diagnosed methaemoglobinaemia. Several of the people required treatment with the antidote methylene blue. All made complete recoveries.

Methaemoglobinaemia is a rare disorder in which the iron atom of haemoglobin oxidises from the ferrous state to the ferric state, leading to reduced oxygen-carrying capacity and cyanosis. Other symptoms and signs include headache, nausea, vomiting, lethargy, shortness of breath, tachycardia and decreased levels of consciousness. Methaemoglobinaemia may be caused by a variety of chemicals including antimalarial and anaesthetic drugs and nitrites. Rarely it may be caused by genetic defects in red blood cells. ${ }^{1}$ The few documented clusters of cases of methaemoglobinaemia recorded in the literature have resulted from misuse of nitrites in food preparation..$^{2-4}$

In response to these reports, public health units were asked to alert emergency departments to report other possible cases. None were identified. In collaboration with the NSW Food Authority and Sydney South West Public Health Unit, epidemiological investigations were carried out to determine a possible link between the two clusters. Interviews with families revealed that in both circumstances the Goldfish brand Nutre Powder had been used in the preparation of food which had been consumed just minutes before the onset of symptoms. In the first cluster, the cases had eaten Nutre Powder used in making rice cakes; in the second cluster, cases had eaten Nutre Powder added to a barbequed pork dish.

The Nutre Powder was purchased from separate Asian grocery stores in the Sydney South West Area. It did not contain any ingredient listing, warnings or instructions for use. Leftover Nutre Powder was collected from the first family and submitted for laboratory testing. Results indicated that this powder was $100 \%$ sodium nitrite. It had 
been imported from China through Victoria from where it was distributed to retailers in Victoria, New South Wales and South Australia. Interviews with various retailers and patrons at various Chinese grocery shops revealed uncertainty about its actual purpose, which ranged from tooth powder to foot powder to food flavour enhancer to meat preservative.

Victorian health authorities initiated a national recall of this product and NSW Health issued a media release advising the public not to consume Goldfish brand Nutre Powder. Ethnic radio and newspaper media were specifically used to target Asian populations. These events highlight the importance of correct labelling and appropriate warnings on packages sold in grocery stores.

\section{Recent increase in haemolytic uraemic syndrome cases}

From November to December 2006 NSW Health received eight notifications of haemolytic uraemic syndrome (HUS). All eight cases had a history of diarrhoeal illness before the onset of HUS, and in three, Shiga toxigenic Escherichia coli (STEC) were detected in stool specimens. Of these, two were identified as E. coli $\mathrm{O} 157$ and one as E. coli $\mathrm{O} 55$. The age of cases ranged from 1 to 27 years (median 6 years) and $56 \%$ were male. There was no geographical clustering of cases.

During November to December 2005, a similar increase was seen with seven HUS cases reported. The public health unit found no common links among the cases. In each of the five years from 2000 to 2004, an average of two HUS cases were reported for the November to December period.

HUS is a severe, sometimes fatal, condition characterised by kidney failure, bleeding and anaemia that more commonly occurs in children. Symptoms of HUS may include bruising or a rash of fine red spots, reduced urination and reduced consciousness. ${ }^{5}$ About $90 \%$ of HUS cases are associated with diarrhoea, and of these, most (at least in the United States) are caused by STEC infections. ${ }^{6}$

Symptoms of STEC infection commonly include diarrhoea that may be bloody, abdominal cramps, nausea and vomiting lasting 5 to 10 days. More commonly recognised strains of STEC include E. coli $\mathrm{O} 111$ and E. coli O157. In about $8 \%$ of cases, infection can lead to HUS. ${ }^{5}$

In many countries cattle are a common reservoir of $\mathrm{STEC}^{7}$ and ingestion of food contaminated with infected cattle faeces (e.g. undercooked burger patties, unwashed salad vegetables, and unpasteurised milk or milk products) is the most common mode of transmission. ${ }^{8}$ STEC infections have also been documented from drinking or swimming in contaminated water. ${ }^{9}$
In light of the recent increase in HUS case notifications, NSW Health initiated enhanced surveillance for STEC infections and HUS. Public health staff alerted paediatric renal units and pathology laboratories throughout the state of the increase, and requested STEC testing on all undiagnosed bloody stools. The eight HUS cases were interviewed for possible food and environmental risks but no common links were identified. STEC infection and HUS can be prevented by: thorough hand washing; safe handling, cooking and storage of food; and by avoiding unpasteurised products.

\section{Influenza surveillance for NSW in 2006}

The 2006 influenza season for NSW was mild. Influenza activity peaked in late August. Two influenza A outbreaks were identified, one in an aged care facility and one in a school. Here we provide an overview of enhanced influenza surveillance program in NSW during the 2006 season.

\section{Background}

Influenza is highly contagious and mainly caused by influenza viruses A and B. The virus is usually spread from person to person through droplets when an infected person coughs or sneezes. People with influenza can help prevent its spread by resting at home while sick, covering their nose and mouth when they cough or sneeze and regularly washing their hands with soap and running water. Symptoms include a sudden onset of fever, headache, muscle and joint pain, tiredness, sore throat, cough and runny or stuffy nose. Symptoms usually appear within 1 to 3 days of being infected, and a person is usually contagious for 3 to 4 days. Up to $30 \%$ of the community could catch influenza each year. Influenza can be prevented by annual vaccination. ${ }^{10}$ Vaccination is available from general practitioners. In recent years in NSW, the influenza season has peaked any time from July to September.

\section{Methods}

The NSW Influenza Surveillance Program runs from May to October each year. Data sources for 2006 included reports of:

- Influenza like illness (ILI) from 30 emergency departments across the greater Sydney area (Auburn, Bankstown, Blacktown, Bowral, Camden, Campbelltown, Canterbury, Children's Hospital at Westmead, Concord, Fairfield, Gosford, Hornsby, Liverpool, Manly, Mona Vale, Mount Druitt, Prince of Wales, Royal North Shore, Royal Prince Alfred, Ryde, Wollongong, Shellharbour, Shoalhaven, St George, St Vincent's, Sutherland, Sydney Hospital, Sydney Children's, Westmead and Wyong hospitals). Rates of ILI less than 2.0/1000 presentations are considered 'low', 2.0 to $3.9 / 1000$ consultations 'moderate', 4.0 to $5.9 / 1000$ consultations 'high' and greater than 6.0/1000 consultations 'very high'. 


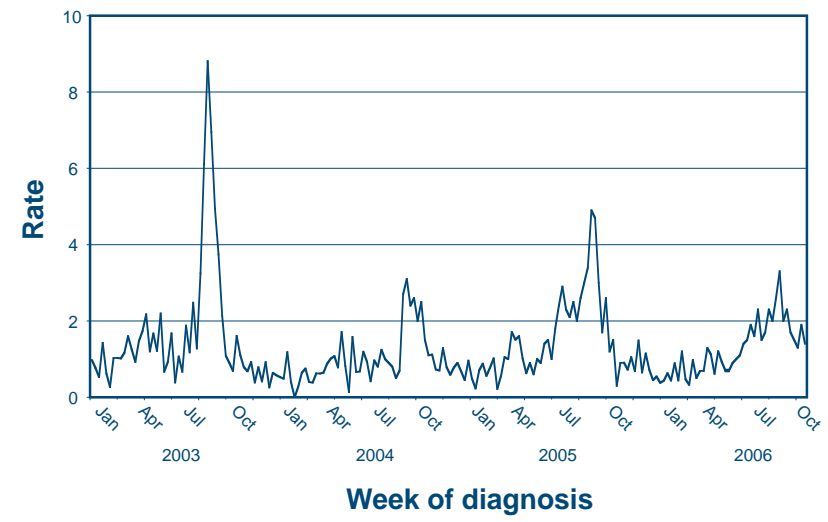

Fig. 1. Rate of influenza like illness per 1000 presentations to participating emergency departments, New South Wales, 1 January 2003 to 6 October 2006

- Laboratory diagnoses of respiratory viral infections by six major public laboratories: South East Area Laboratory Service (SEALS), Institute of Clinical Pathology and Medical Research (ICPMR), South West Area Pathology Service (SWAPS), Pacific Laboratory Medicine Service (PaLMS), Hunter Area Pathology Service (HAPS) and Children's Hospital at Westmead (CHW). All six laboratories provided virology reports, and three (SEALS, ICPMR and HAPS) also provided serology reports.

- National and international influenza activity from the World Health Organization Collaborating Centre for Reference and Research on Influenza, Melbourne. ${ }^{11}$

The surveillance program monitors general trends in influenza rather than the total number of people who are infected each year.

\section{Results}

\section{Emergency Department surveillance}

For the majority of the 2006 influenza season, ILI rates from emergency departments were low. The highest reported rate (3.3 per 1000 presentations) occurred in late

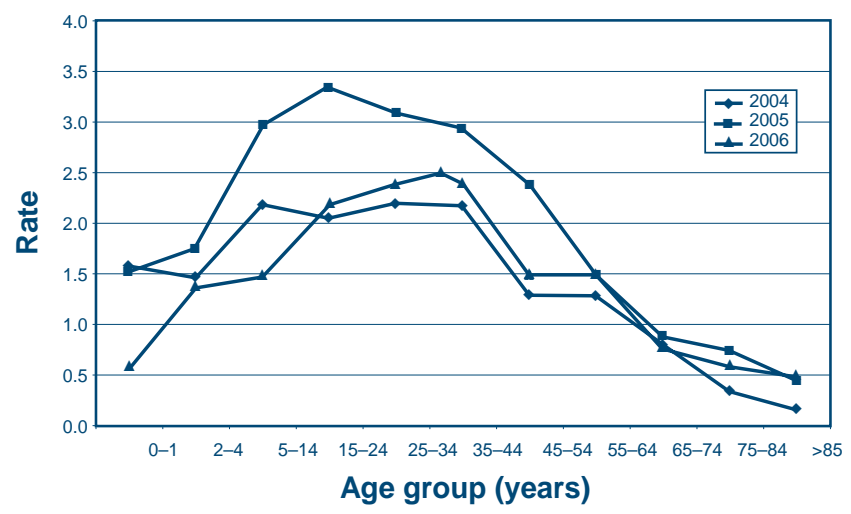

Fig. 2. Rate of influenza like illness per 1000 presentations to participating emergency departments, by age group, New South Wales, 2004 to 2006

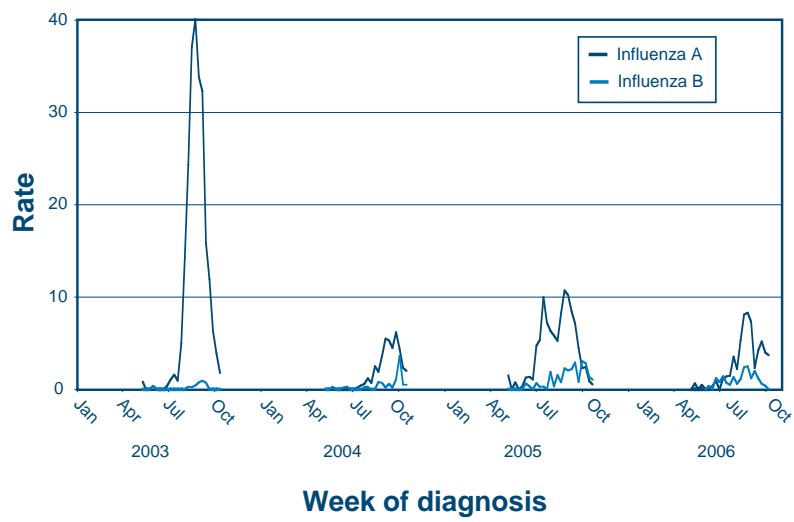

Fig. 3. Rate of influenza virus detection by direct immunofluorescence per 100 samples for six major public laboratories, New South Wales, 1 May 2003 to 6 October 2006

August. The mean rate of ILI presentations was 1.7 per 1000 presentations (range $0.7-3.3$ ). In 2005, the mean rate was 2.3 per 1000 presentations (range $0.3-4.9$ ). In total, $40 \%$ of cases diagnosed with an ILI were aged 15-34 years, $12 \%$ were children under the age of 5 years. Overall, $6 \%$ of ILI cases presenting to emergency departments were admitted to hospital (Figs 1 and 2).

\section{Laboratory surveillance}

Virology: For the 2006 surveillance period, 12356 respiratory samples were tested for influenza and other respiratory viruses. Of these 268 (2\%) were positive for influenza A (by direct immunofluorescence (DIF), polymerase chain reaction (PCR) or culture). The highest rate reported (8.1 per 100 samples, by DIF) was for the week ending 20 August. The mean DIF rate was 2.6 per 100 samples. The mean DIF rate for 2005 was 3.0 per 100 samples. The majority of positive influenza samples in 2006 came from children less than 5 years (46\%) (Fig. 3; Table 1).

Of all samples, 119 (1\%) tested positive for influenza B (by DIF, PCR or culture). The highest rate (DIF rate 2.5 per 100 samples) was recorded week ending 27 August. The mean DIF rate was 0.8 per 100 samples, which was similar to that reported in 2005 (DIF rate 1.0 per 100 samples) (Fig. 3; Table 1).

Serology: For the 2006 surveillance period the six participating laboratories tested 2720 serum samples for evidence of infection with influenza (characterised by seroconversion or rise in $\mathrm{IgG}$ level or high single titre to influenza virus or RSV). Of these, 77 samples (2.8\%) had a high serological titre and $28(1 \%)$ had a 4 -fold rise in titre for influenza A. The highest rate (9.7 per 100 samples) was reported in the week ending 14 July. The mean rate in 2006 (3.9 per 100 samples) was lower than in 2005 (6.0 per 100 samples) (Table 2).

Sixty samples $(2.2 \%)$ had a high serological titre and one $(<0.1 \%)$ had a 4 -fold rise in titre for influenza B. There 
Table 1. Results of 7202 respiratory specimens tested by direct immunofluoescence, and week of peak activity, for six major laboratories, New South Wales, 29 April to 6 October 2006

\begin{tabular}{lrrlrc}
\hline Virus & Peak number positive & \multicolumn{2}{c}{ Week-ending for } & \multicolumn{2}{c}{ Total number positive } \\
& $n$ & $\%$ & peak number positive & $n$ & $\%$ \\
\hline Influenza B & 11 & 16 & 25 August & 67 & 1 \\
Adenovirus & 8 & 9 & 8 September & 86 & 1 \\
Para influenza 1 & 5 & 17 & 23 June & 30 & 0.4 \\
Para influenza 2 & 1 & 17 & 26 May & 6 & 0.08 \\
Para influenza 3 & 15 & 13 & 22 September & 113 & 2 \\
RSV & 190 & 12 & 14 July & 1628 & 23 \\
Rhinovirus & \multicolumn{7}{c}{ Number too small to judge } & 3 & 0.04 \\
\hline
\end{tabular}

were two small peaks identified throughout the season, a rate of 6.0 per 100 samples for the week ending 19 May and a rate of 5.6 per 100 samples for the week ending 26 July. The mean rate for 2006 ( 2.2 per 100 samples) was higher than in 2005 (1.5 per 100 samples) (Table 2).

\section{Outbreaks}

Two influenza outbreaks were reported in 2006. The first was in an aged care facility within the Greater Western Area Health Service. In total, 7 of 17 residents and one staff member reported ILI symptoms. Nose and throat swabs were taken from six residents and four of these were positive for influenza A. The second outbreak was reported from a high school in the Hunter/New England Area. More than 120 students presented with ILI symptoms and six cases were admitted to the local hospital with pneumonia. Nose and throat swabs were taken from several students of which six were positive for influenza A by PCR. Eight blood cultures were taken of which two grew Streptococcus pneumoniae (serotype 1). For both outbreaks a range of control measures were implemented following the national guidelines. ${ }^{12}$

\section{National and international situation}

Up to 26 October 2006, Queensland had the highest number of influenza notifications (1175) followed by NSW (476), Victoria (388) and Western Australia (189). ${ }^{11}$
The World Health Organization Collaborating Centre for Reference and Research on Influenza in Melbourne had analysed 562 influenza strains supplied by laboratories in Australia as at 20 October 2006. Of these, 22 were A (H1) strains, 320 were A (H3) strains and 220 were B strains. The majority of B strains (206) were Malaysia-like while the remainder (14) were Shanghai-like. Of the 2411 laboratory-confirmed cases reported in 2006, 1667 (69.1\%) were type A, $656(27.2 \%)$ were type B, 31 cases $(1.3 \%)$ were typed as $\mathrm{A} \& \mathrm{~B}$ and for 57 cases (2.4\%) type was not reported. ${ }^{13}$

The World Health Organization reports that during the period February to September 2006, influenza A (H1N1), A (H3N2) and B viruses circulated in many parts of the world. ${ }^{12}$

- Influenza A (H1N1) viruses were associated with outbreaks in Africa (Egypt), the Americas (Brazil), Asia (Hong Kong SAR, China, Japan and Thailand) and Europe (Spain). The majority of isolates were similar to A/New Caledonia/20/99.

- Influenza A (H3N2) viruses were also associated with widespread outbreaks in several countries. Most recent isolates were similar to the vaccine viruses

A/Wisconsin/67/2005 and A/Hiroshima/52/2005.

Table 2. Results of 2720 respiratory specimens tested by serology, and week of peak activity, for six major laboratories, New South Wales, 29 April to 6 October 2006

\begin{tabular}{|c|c|c|c|c|c|}
\hline \multirow[t]{2}{*}{ Virus } & \multicolumn{2}{|c|}{ Peak number positive } & \multirow{2}{*}{$\begin{array}{l}\text { Week-ending for } \\
\text { peak number positive }\end{array}$} & \multicolumn{2}{|c|}{ Total number positive } \\
\hline & $n$ & $\%$ & & $n$ & $\%$ \\
\hline Influenza A & 14 & 13 & 21 July & 105 & 4 \\
\hline Influenza B & 5 & 8 & 18 August & 61 & 2 \\
\hline Adenovirus & 2 & 20 & 8 September & 10 & 0.4 \\
\hline Para influenza 1 & 5 & 33 & 14 July & 15 & 0.6 \\
\hline Para influenza 2 & 4 & 50 & 4 August & 8 & 0.3 \\
\hline Para influenza 3 & \multicolumn{3}{|c|}{ Number too small to judge } & 3 & 0.1 \\
\hline RSV & \multicolumn{3}{|c|}{ Number too small to judge } & 7 & 0.3 \\
\hline Rhinovirus & \multicolumn{3}{|c|}{ Number too small to judge } & 0 & 0 \\
\hline
\end{tabular}


- Influenza B outbreaks were reported in many countries in Asia and Europe, and in Egypt and the United States. The majority of recent isolates were similar to B/Malaysia/2506/2004 (B/Victoria/2/87 lineage).

\section{7 vaccine}

The composition of the influenza vaccine is determined annually by the World Health Organization and the Australian Vaccine Committee based on current influenza circulating viruses. The recommended ${ }^{13}$ composition of influenza vaccine (Southern Hemisphere) for 2007 is:

- A/New Caledonia/20/99

- $\mathrm{A} /$ Wisconsin/67/2005

- B/Malaysia/2506/2004.

Influenza surveillance report prepared by Communicable Diseases Branch, NSW Health, in collaboration with: NSW Emergency Department Data Collection (HOIST), and NSW Public Health Real-time Emergency Department Surveillance System (Centre for Epidemiology and Research, NSW Department of Health), South East Area Laboratory Service (SEALS), Institute of Clinical Pathology and Medical Research (ICPMR), South West Area Pathology Service (SWAPS), Pacific Laboratory Services (PaLMS), Hunter Area Pathology Service (HAPS), New Children's Hospital (CHW). Enquiries to Robin Gilmour, ph. 029424 5875, email: rgilm@doh.health.nsw.gov.au

\section{References}

1. Rehman HU. Methemoglobinemia West J Med 2001; 175(3): 193-6. doi:10.1136/ewjm.175.3.193

2. Askew GL, Finelli L, Genese CA, Sorhage FE, Sosin DM, Spitalny KC. Boilerbaisse: an outbreak of methemoglobinemia in New Jersey in 1992. Pediatrics 1994; 94(3): 381-4.

3. Kennedy N, Smith CP, McWhinney P. Faulty sausage production causing methaemoglobinaemia. Arch Dis Child 1997; 76(4): 367-8.
4. Centres for Disease Control and Prevention (CDC) Methemoglobinemia following unintentional ingestion of sodium nitrite-New York, 2002 MMWR Morb Mortal Wkly Rep 2002; 51(29): 639-42.

5. Heymann DL, editor. Control of Communicable Diseases Manual, 18th edn. Washington DC: American Public Health Association, 2004.

6. http://www.cdc.gov/ncidod/eid/vol3no3/mahon.htm. Accessed 3 April 2007.

7. Hussein HS, Bollinger LM. Prevalence of Shiga toxinproducing Escherichia coli in beef cattle. J Food Prot 2005; 68(10): 2224-41.

8. Bell BP, Goldoft M, Griffin PM, Davis MA, Gordon DC, Tarr PI et al. A multistate outbreak of Escherichia coli O157:H7-associated bloody diarrhea and hemolytic uremic syndrome from hamburgers. The Washington experience. JAMA 1994; 272(17): 1349-53. doi:10.1001/jama.272.17.1349

9. Keene WE, McAnulty JM, Hoesly FC, Williams LP Jr, Hedberg K, Oxman GL et al. A swimming-associated outbreak of hemorrhagic colitis caused by Escherichia coli $\mathrm{O} 157: \mathrm{H} 7$ and Shigella sonnei. N Engl J Med 1994; 331(9): 579-84. doi:10.1056/NEJM199409013310904

10. National Health \& Medical Research Council. The Australian Immunisation Handbook, 8th edn. Canberra: AGPS, 2003.

11. Communicable Diseases Network Australia. Guidelines for the prevention and control of influenza outbreaks in residential care facilities. Australian Government Department of Health and Ageing, 2005. http://www.health.gov.au/internet/wcms/ publishing.nsf/content/cda-pubs-other-flu_guidel.htm. Accessed 3 April 2007.

12. WHO Collaborating Centre for Reference and Research on Influenza, Parkville Victoria. http://www.influenzacentre.org. Accessed 3 April 2007.

13. WHO Global Influenza Surveillance Network, Geneva. http://www.who.int/csr/disease/influenza/surveillance/en/ Accessed 3 April 2007. 
Fig. 4. Reports of selected communicable diseases, NSW, Jan 2001 to December 2006, by month of onset. Preliminary data: case counts in recent months may increase because of reporting delays. Laboratory-confirmed cases only, except for measles, meningococcal disease and pertussis.

$\mathrm{BFV}=$ Barmah Forest virus infections, RRV $=$ Ross River virus infections, Laboratory Conf $=$ laboratory confirmed, Men

$\mathrm{Gp} C$ and $\mathrm{Gp} B=$ meningococcal disease due to serogroup $C$ and serogroup $B$ infection, other/unk = other or

unknown serogroups. N.B.: multiple series in graphs are stacked, except gastroenteritis outbreaks. NB. Outbreaks are more likely to be reported by nursing homes \& hospitals than by other institutions

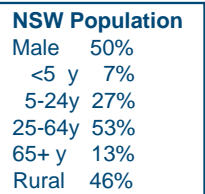
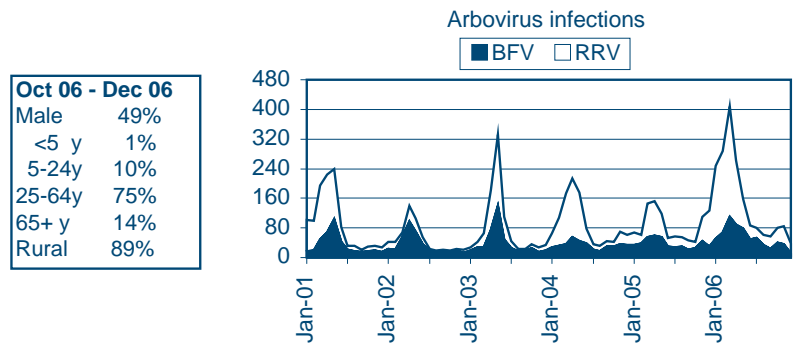

Cryptosporidiosis

\begin{tabular}{|cc|}
\hline Oct 06 & - Dec 06 \\
Male & $49 \%$ \\
$<5$ y & $40 \%$ \\
$5-24 y$ & $37 \%$ \\
$25-64 y$ & $21 \%$ \\
$65+y$ & $2 \%$ \\
Rural & $70 \%$ \\
\hline
\end{tabular}

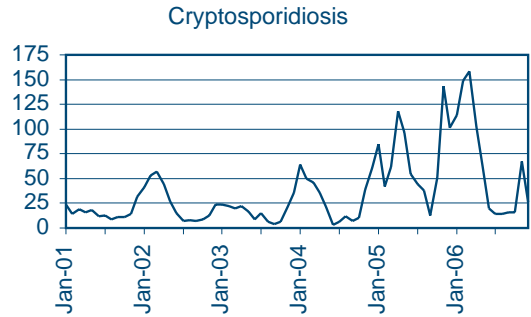

Gastroenteritis outbreaks in institutions

\begin{tabular}{|lr|}
\hline Oct 06 - Dec 06 \\
All outbreaks & 60 \\
Nursing homes & 32 \\
Hospitals & 14 \\
Child care & 11 \\
Schools & 0 \\
Other & 3 \\
\hline
\end{tabular}

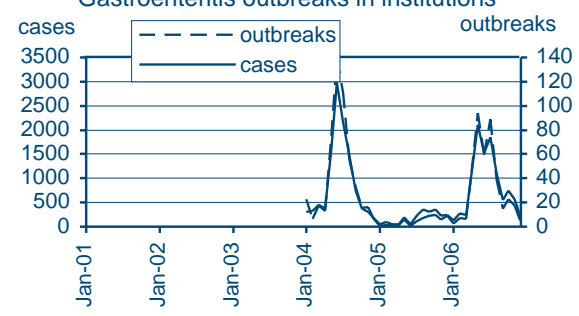

Gonorrhoea

\begin{tabular}{|lc|}
\hline Oct 06 & - Dec 06 \\
Male & $87 \%$ \\
$<5$ y & $0 \%$ \\
$5-24 y$ & $18 \%$ \\
$25-64 y$ & $81 \%$ \\
$65+y$ & $1 \%$ \\
Rural & $13 \%$ \\
\hline
\end{tabular}

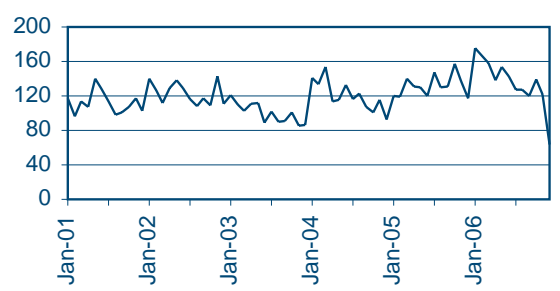

Hepatitis A

\begin{tabular}{|cc|}
\hline Oct 06 & - Dec 06 \\
Male & $30 \%$ \\
$<5$ y & $0 \%$ \\
$5-24 y$ & $30 \%$ \\
$25-64 y$ & $50 \%$ \\
$65+y$ & $20 \%$ \\
Rural & $10 \%$ \\
\hline
\end{tabular}
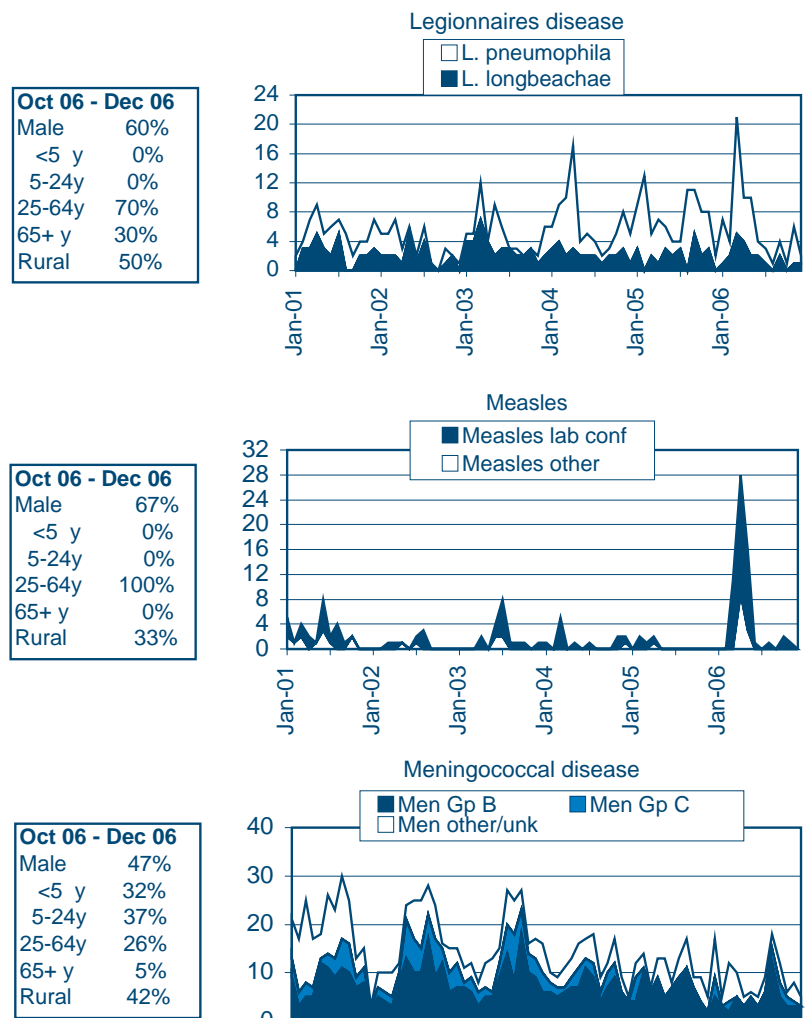

Measles

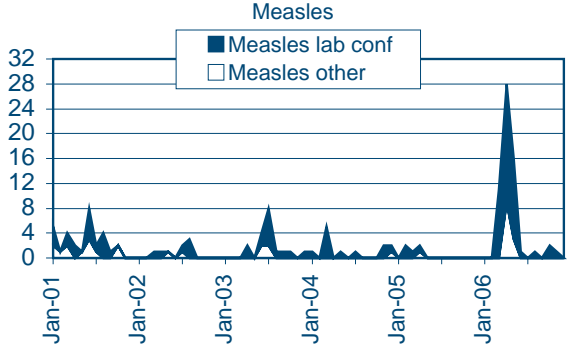

Meningococcal disease

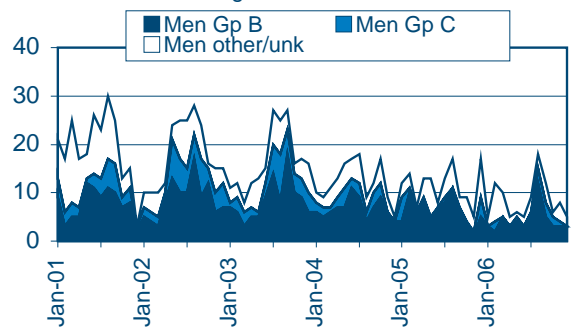

Oct 06 - Dec 06 Male $43 \%$

$<5$ y $9 \%$ $5-24$ y $10 \%$ $25-64 y \quad 63 \%$ $65+y \quad 18 \%$ Rural $49 \%$

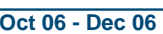

Male $\quad 49 \%$

$<5$ y $24 \%$

$5-24 y \quad 29 \%$

$25-64 y \quad 37 \%$

$65+y \quad 10 \%$

Rural $42 \%$
Pertussis
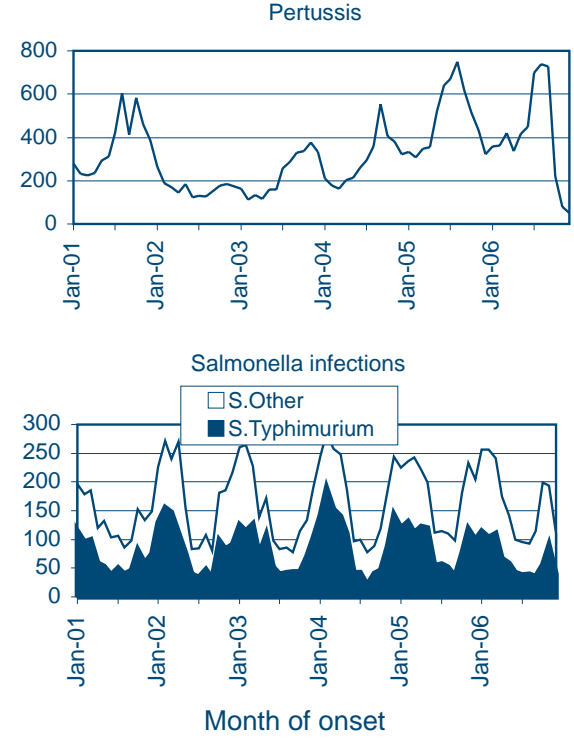
Table 3. Reports of notifiable conditions received in November 2006 by area health services

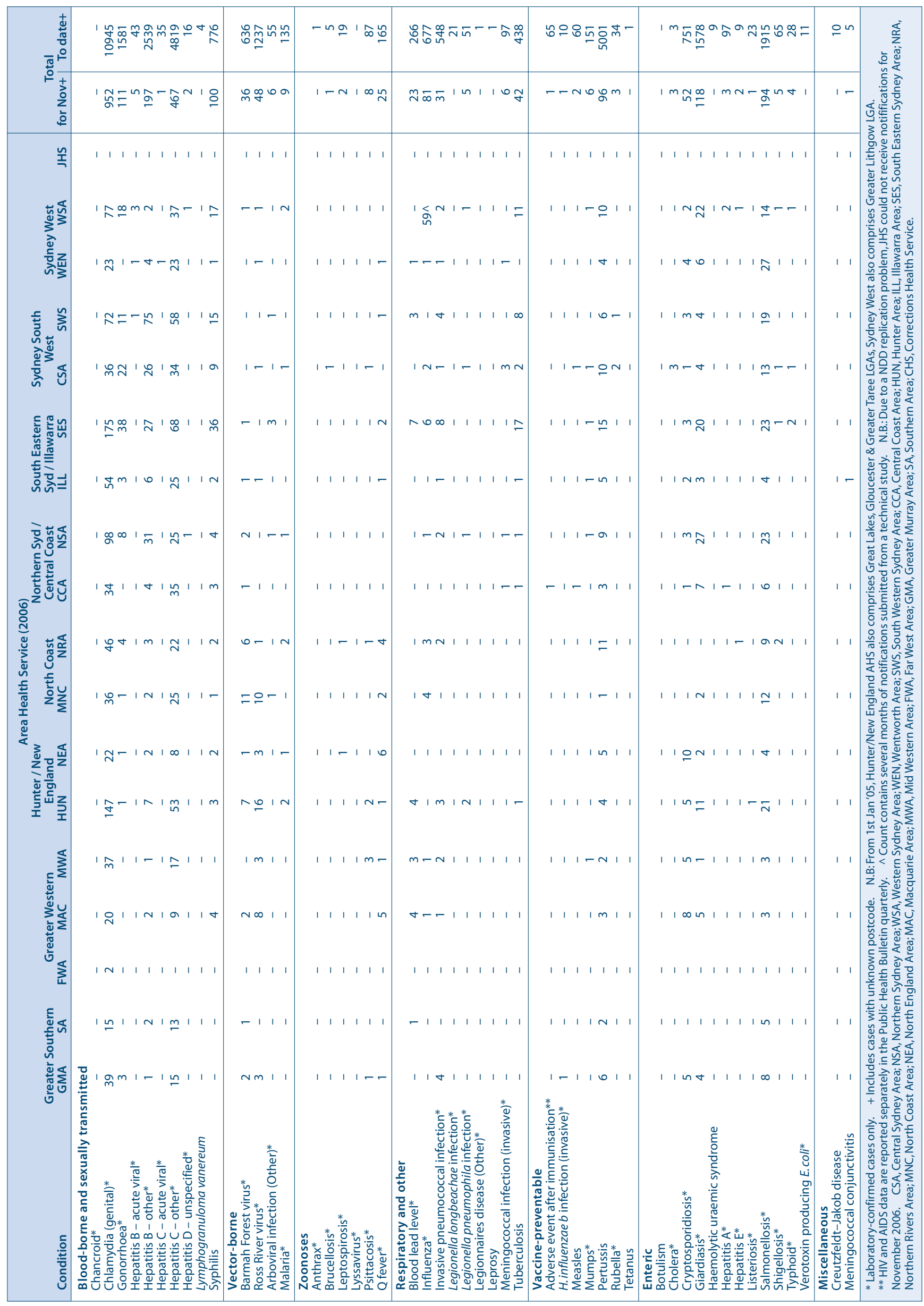


Table 4. Reports of notifiable conditions received in December 2006 by area health services

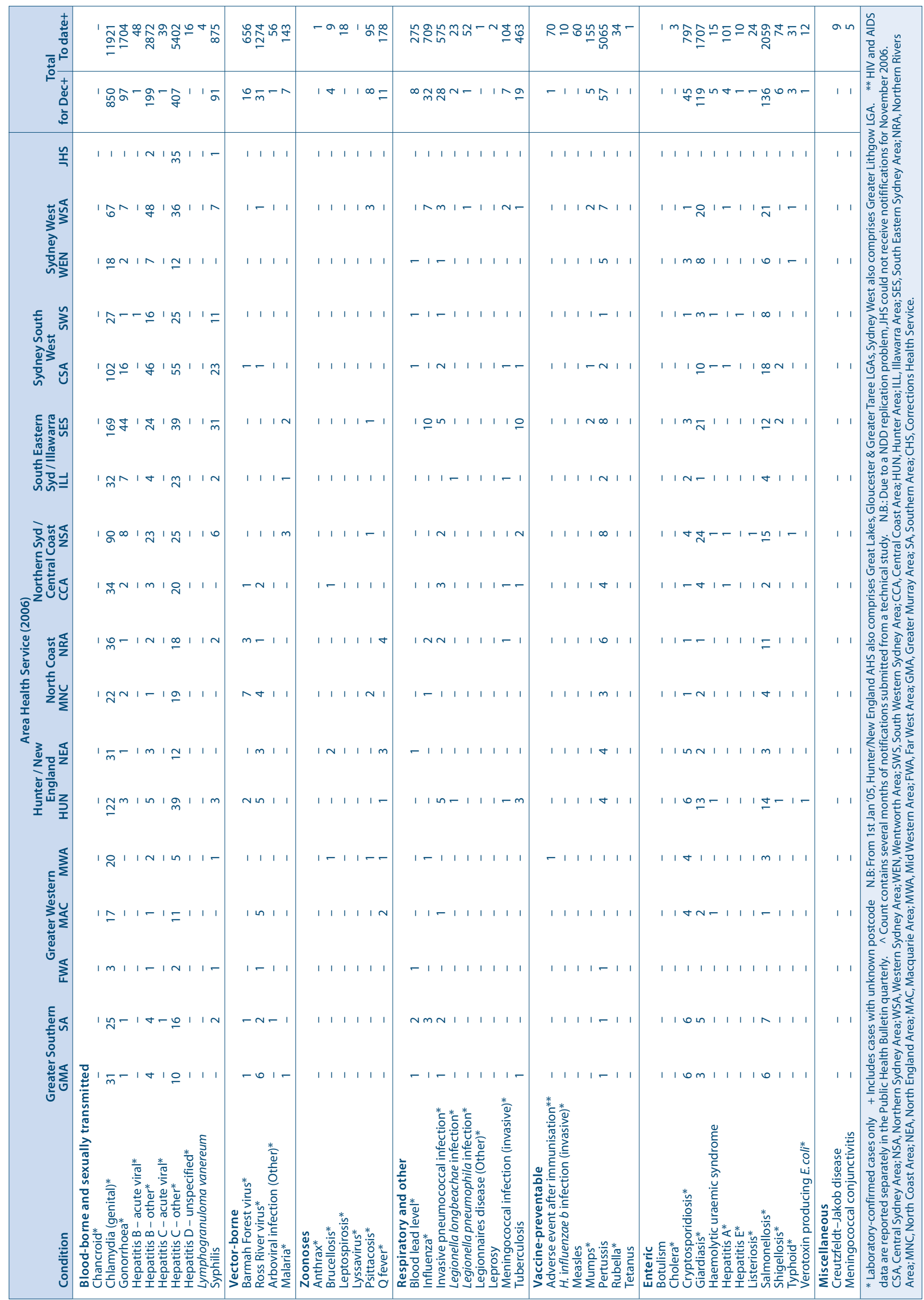

